\title{
LA MUJER EN LA SHOA: SU ROL DE CUIDADORA ${ }^{1}$
}

The woman in the shoa: its career's role

\author{
Ximena H. Cortez G. ${ }^{2}$ \\ Centro de Estudios Judaicos \\ Universidad de Chile \\ xhcortez@yahoo.com
}

\section{RESUMEN}

El Presente trabajo se centra en un número específico de mujeres que han dejado sus memorias como testimonio para una humanidad que siempre ha necesitado mantener vivos sus testimonios. Nuestro interés está dirigido a mantener sus recuerdos del pasado hasta nuestros días, recobrando los significados esenciales de sus vidas. Creo que es apropiado decir que no creemos que las experiencias de las mujeres en la Shoá hayan sido muy diferentes de las de los varones pero sus historias con ciertamente dignas de ser rescatadas.

Palabras claves: Mujeres, shoa, $2^{\mathrm{a}}$ guerra mundial, genero, Auschwitz, campos de concentración.

\section{ABSTRACT}

The present work focuses on a specific number of women who have left their memories as a proof for mankind that has always needed to keep their testimonies alive. Our main interest is to maintain the remembrances from the past until today, capturing the essential meanings of their lives. We believe it is appropriate to claim that although women's experiences during the Holocaust were not quite different from those of men, their stories are certainly worthy of being rescued.

Key words: Women, Shoah, World War II, gender, Auschwitz, concentration camps.

\footnotetext{
${ }^{1}$ Publicado en Cuadernos Judaicos No 27 (2010).

${ }^{2}$ Académica Centro de Estudios Judaicos y del Departamento de Estudios Pedagógicos, de la Facultad de Filosofía y Humanidades de la Universidad de Chile.
} 
Sin memoria no tenemos presente, futuro ni esperanza, las sobrevivientes de la Shoah están llegando al tiempo de partir. Su tiempo se acaba y con él las vivencias de muchas, muchísimas mujeres que lograron, primero sobrevivir y luego reconstruir sus vidas, creando nuevos significados para sus recuerdos. A nosotros nos cabe la responsabilidad de mantener vivas sus voces testimoniales, a fin que nunca se extinga una parte de nuestra historia.

En este sentido, trataremos cómo el rol de género, en su calidad de constructo cultural, incidió, por una parte, en el tratamiento que recibieron las mujeres en el Holocausto y, por otra parte, cómo estas mismas mujeres asumieron su manera de ser y estar en dichas circunstancias.

El objetivo de este tipo de historia desde la perspectiva de género es describir lo singular femenino con el intento de llegar "a través de lo femenino a lo humano"

El individuo y la vida cotidiana están en el centro de la observación del historiador social. Así, es posible devolver a las víctimas sus caras humanas e individuales.

Analizar acerca del destino y de los problemas peculiares de las mujeres nos ayuda a discernir la especificidad de la vida cotidiana y las distintas maneras en que los hombres y las mujeres respondieron al ataque de los nazis.

Usar el género como un marco para el análisis simplemente es prestar mayor atención a las posibles consecuencias de uno de los ejes más importantes de toda organización social, junto con la edad, la clase socio-económica, la etnia y la religión.

Existieron muchas instancias en que la experiencia de un individuo se conformó por su género y sólo al comprender lo que fue peculiar de las mujeres -y lo que fue peculiar de los hombres- podemos proporcionar una descripción completa de lo que sucedió. 
En este trabajo no describiremos las condiciones de vida de las mujeres en los campos de concentración, aunque sabemos de sus tratamientos "especiales" dados por los nazis precisamente por su condición de mujeres; sabemos de cómo protegieron a sus hijos, parejas, hermanos, padres, etc.

Más bien, nuestro interés se dirige a aquellas mujeres que han dejado sus memorias como cuidando a una humanidad que siempre las ha necesitado.

Según Hannah Arendt, el ámbito de los proyectos humanos, en el espacio público, está conformado por las interacciones que se instituyen entre los seres humanos dondequiera que vivan juntos. El impulso nuevo que nos mueve a adentrarnos en el habitus de la problemática humana se da, según la autora, a partir de nuestro nacimiento. Cada nacimiento implica la singularidad de lo nuevo y único que llega al mundo, a la manera de un acontecimiento absolutamente inesperado. Al nacer como seres únicos, los seres humanos toman la decisión y se disponen a la acción. En la naturaleza del inicio, el nacimiento, dice Arendt, se basa la realización de algo novedoso, que nunca antes ha ocurrido. Así, facultades como el hecho del discurso y el acto se revelan como sustento de la libertad y la singularidad humanas. De la misma manera, por ser toda acción inicio, es en sí misma ilimitada, impredecible y sus consecuencias son irreversibles (Arendt, H., 2005).

Hannah Arendt, apoya estas reflexiones en el pensamiento del humanismo cristiano propio de San Agustín. De este autor toma la idea de que el ser humano surge como un ser cuya existencia está dirigida a comenzar procesos históricos completamente nuevos debido a que, desde un plano temporal, es en sí un comienzo, es decir, algo ontológicamente novedoso. No obstante, el ser humano es y sabe que es persona, y junto a esta conciencia tiene la facultad para explorar su origen y ubicarse teleológicamente.

"El milagro que salva al mundo, nos dice en uno de los párrafos más 
bellos de La condición humana, a la esfera de los asuntos humanos, de su ruina normal y natural es en último término el hecho de la natalidad, en el que se enraíza ontológicamente la facultad de la acción (...): el nacimiento de nuevos hombres y un nuevo comienzo, es la acción que son capaces de emprender los humanos por el hecho de haber nacido. Sólo la plena experiencia de esta capacidad puede conferir a los asuntos humanos fe y esperanza (...). Esta fe y esperanza en el mundo encontró tal vez su más gloriosa y sucinta expresión en las pocas palabras que en los evangelios anuncian la gran alegría: Os ha nacido hoy un Salvador" (Arendt, H., 2005)

Ciertamente, esta aptitud para la acción, lleva a que el ejercicio de la libertad sea para Arendt, el comienzo de los acontecimientos que vincularán existencialmente a las personas. Esto es, en virtud de que la realidad humana no se limita a la singular vida del ser humano, sino a las vidas de los hombres y mujeres, lo que éstos hacen o dejan de hacer libremente siempre tiene una incidencia, directa o indirectamente, en la vida de los demás.

Todo esto requiere de ámbitos de develamientos, capaces de transparentar acciones y sentires. Acaso, a manera de catarsis de lo humano, de nuestras historias personales y colectivas.

Intentaremos aproximarnos a estas reflexiones.

\section{¿POR QUÉ LAS MUJERES?}

Ciertamente, las circunstancias de las mujeres en la Shoah no se estudia aparte, más bien se inserta dentro del marco general en los campos de concentración y fuera de ellos, en todo lo que aconteció con los judíos de ambos sexos.

Este trabajo tiene, como ya se dijo, la intención de mirar cómo se dio la significación de género en la Shoah y, sobre todo mostrar, a través del estudio de caso, cómo las mujeres 
entendieron sus vivencias, en sus escritos antes de ser muertas por el régimen nazi.

Creemos que es pertinente afirmar que no pensamos que las experiencias de las mujeres, en el Holocausto, fueron absolutamente diferentes a la de los hombres. Eso sería tan equívoco como decir que fueron idénticas. Sin embargo, existieron muchas instancias en que la experiencia de un sujeto se conformó por su género y únicamente entendiéndolo así, es posible comprender totalmente lo ocurrido.

Nuestro foco de investigación, se centra en la vida de cuatro mujeres: Edith Stein, Etty Hillesum, Simone Weil y Ana Frank. Todas diferentes y, sin embargo, enfrentadas a un destino común que las llevó finalmente a la muerte. Todas ellas se unen en la escritura, acción que les permitió mirar su situación con la perspectiva de quien entiende lo que le está pasando y desea alejarse de esa realidad sumergiéndose en ella, con sus escritos, en los cuales plasmaron sus sentires y, después de todo, resistieron y traspasaron su ethos epocal, transformándose en memoria y, al decir de Hannah Arendt, en esperanza.

\section{Edith Stein}

Una de los miles de víctimas se llama Edith Stein, mujer que ha seguido el mismo destino de millones de hombres que encontraron la muerte sólo por el delito de pertenecer a la raza judía. Pero Edith también ha sido llevada al suplicio por ser católica, dos facetas de su vida que le hacen ser un personaje muy atractivo y de gran interés, sobre todo para la discusión que sobreviene luego de su canonización.

Ella es una de esas personas que parecen haber nacido bajo un signo. Nació en Yom Kippur, el Día del Perdón para el pueblo judío, el año 1891, en Alemania. Fue la hija menor, de once hijos, en el seno de una devota familia judía.

Fue una de las primeras mujeres en ser admitida para seguir estudios superiores en la Universidad de Breslau, y desde allí se trasladó a la Universidad de Gottingen, para 
seguir sus estudios con Edmund Husserl, fundador de la fenomenología, y de quien se convirtió en su asistente. En esta etapa de su vida era no creyente.

Podemos acercarnos a su pensamiento a través de la carta que escribe a su hermana Erna, el 6 de julio de 1918:

Freiburg, 6.7.1918

Mi querida Erna:

“.... Me duele mucho encontrar en ti y en Rose expresiones tan pesimistas. Gustosamente quisiera transmitiros algo de lo que a mí, después de cada nuevo golpe, me da nueva energía. Solo puedo deciros que, después de cuanto he aguantado en el último año, doy un sí a la vida con más decisión que nunca. Te envío un artículo de Rathenau para que veas que sobre las perspectivas de la guerra otras personas piensan poco más o menos como yo. Ciertamente, a veces creo que hay que hacerse a la idea de que una no va a ver el fin de la guerra. Aún entonces no hay que desesperarse. Lo que hay que hacer es no limitarse únicamente al trocito de vida que abarca nuestra vista, y mucho menos a aquello que clarísimamente está en la superficie. Es muy seguro que nos encontramos en un punto crítico dentro del desarrollo del espíritu humano, y no hay que quejarse si la crisis dura más de lo que cada uno en particular desearía. Todo lo que ahora es tan horrible, y que yo, desde luego, no quiero disimular, es el espíritu que debe ser superado. Pues el nuevo espíritu está ya ahí y, sin lugar a dudas, terminará por imponerse. Lo tenemos muy patente en la filosofía y en los inicios del nuevo arte: el expresionismo... Lo bueno y lo malo, el conocimiento y el error están mezclados en todas partes, y cada uno ve en sí mismo sólo lo positivo y en los demás sólo lo negativo, trátese de pueblos como de partidos. Esto desencadena una espantosa confusión, y quién sabe cuándo aparecerá otra vez algo de calma y claridad. En todo caso, la vida es demasiado complicada como para poder arremeter contra ella con un plan de mejora del mundo, por bien pensado que esté, y como para poder imponer a dicho plan el camino que, de forma definitiva e inequívoca, ha de seguir.... Sólo quisiera inculcarte la confianza de que el desarrollo, cuyo curso nosotros presentimos sólo muy limitadamente y mucho más limitadamente podríamos determinar, a fin de cuentas es algo bueno. 
Saludos cordiales y besos, tuya Edith."

Durante el verano de 1921, durante sus vacaciones leyó a Santa Teresa de Ávila, fundadora de la Orden de las Carmelitas. Fue bautizada en enero del año siguiente, sin embargo, no entró al convento inmediatamente, como al parecer era su deseo.

Tras su conversión, Edith se dedicó a la docencia y la escritura, siendo pronto conocida como una reconocida filósofa y llegó a ser la voz católica del Movimiento de Mujeres en Alemania.

La llegada al poder del nazismo, trajo la persecución, con todo tipo de restricciones para el pueblo judío. De alguna manera esto apresuró el consentimiento de su guía espiritual y logró entrar a las Carmelitas Descalzas, el año 1933, transformándose en Sor Teresa Benedicta de la Cruz. Al aumentar las persecuciones, pidió su traslado a Holanda. Allí escribió su último libro La ciencia de la Cruz.

Finalmente los nazis invadieron Holanda y cuando los obispos holandeses escribieron una carta pastoral en protesta por la deportación de los judíos y la expulsión de los niños judíos de las escuelas católicas, los nazis arrestaron a todos los católicos de origen judío. Edith fue tomada prisionera el 2 de agosto de 1942 y trasladada a Auschwitz. Murió en las cámaras de gas el 9 de agosto de 1942.

Una sobreviviente describió estos últimos días de Edith, “"'Tal vez la mejor manera en que puedo explicar es que llevó tanto dolor que duele ver su sonrisa... En mi opinión, ella estaba pensando en el sufrimiento que se nos avecinaba. No en su propio sufrimiento..."

La carta sellada de Sta. Teresa Benedicta de la Cruz (Edith Stein) a S.S. Pío XI sobre la persecución de los judíos en Alemania. 


\section{“Santo Padre!}

Como hija del pueblo judio, que, por la gracia de Dios, desde hace once años es también hija de la Iglesia católica, me atrevo a exponer ante el Padre de la Cristiandad lo que oprime a millones de alemanes.

Desde hace unas semanas vemos sucederse acontecimientos en Alemania que suenan a burla de toda justicia y humanidad, por no hablar del amor al prójimo. Durante años los jefes (Führer) nacionalsocialistas han predicado el odio a los judios. Después de haber tomado el poder gubernamental en sus manos y armado a sus aliados, -entre ellos a señalados elementos criminales-, ya han aparecido los resultados de esa siembra de odio. Hace poco el mismo gobierno admitió el hecho de que ha habido excesos. No nos podemos hacer una idea de la amplitud de estos hechos porque la opinión pública está amordazada. Pero a juzgar por lo que he venido a saber por informaciones personales, de ningún modo se trata de casos aislados. Bajo presión de voces del extranjero, el régimen ha pasado a métodos más "suaves". Ha dado la consigna de que no se debe "tocar ni un pelo a ningún judio”. Pero con su declaración de boicot, lleva a muchos a la desesperación, pues con ese boicot roba a los hombres su mera subsistencia económica, su honor de ciudadanos y su patria. Por noticias privadas he conocido en la última semana cinco casos de suicidio a causa de estas persecuciones. Estoy convencida de que se trata sólo de una muestra que traerá muchos más sacrificios. Se pretende justificar con el lamento de que los infelices no tienen suficiente fuerza para soportar su destino. Pero la responsabilidad cae en gran medida sobre los que lo llevaron tan lejos. Y también cae sobre aquellos que guardan silencio sobre esto. Todo lo que ha acontecido y todavía sucede a diario viene de un régimen que se llama "cristiano". Desde hace semanas, no solamente los judios, sino miles de auténticos católicos en Alemania, y creo que en el mundo entero, esperan y confían en que la Iglesia de Cristo levante la voz para poner término a este abuso del nombre de Cristo. ¿Esa idolatría de la raza y del poder del Estado con la que día a día se machaca por radio a las masas, acaso no es patente herejía? ¿No es la guerra de exterminio contra la sangre judía un insulto a la Sacratísima Humanidad de Nuestro Redentor, a la Santísima Virgen y a los apóstoles? ¿No está todo esto en absoluta contradicción con el comportamiento de Nuestro Señor y Salvador quien aún en la Cruz rogó por sus perseguidores? ¿Y no es esto una negra mancha en la crónica de este Año Santo que debería ser 
un año de paz y de reconciliación?

Todos los que somos fieles e hijos de la Iglesia y que consideramos con ojos despiertos la situación en Alemania nos tememos lo peor para la imagen de la Iglesia si se mantiene el silencio por más tiempo. Somos también de la convicción de que a la larga ese silencio de ninguna manera podrá obtener la paz con el actual régimen alemán. La lucha contra el catolicismo se llevará por un tiempo en silencio, y por ahora con formas menos brutales que contra el judaísmo, pero no será menos sistemática. No falta mucho para que pronto, en Alemania, ningún católico pueda tener cargo alguno si antes no se entrega incondicionalmente al nuevo rumbo.

A los pies de su Santidad pide la Bendición Apostólica

Dr. Edith Stein

Profesora en el Instituto Alemán de Pedagogía científica."

En 1998, fue canonizada por el Papa Juan Pablo II.

En su obra Ser finito y ser eterno, por ejemplo, escribe:

"La esencia del alma es estar abierta hacia dentro. Cuando el yo vive en el fondo de su ser, allí, donde encuentra su pertenencia de hogar, entonces percibe algo del sentido del Ser, la fuerza concentrada de la cual participa. Y cuando vive desde allí entonces vive a plenitud y alcanza la cima del ser y el contenido del Ser se le hace consustancial, carne y sangre dentro de uno mismo y es fuente inagotable de fuerza y vida".

Para Edith la "solución final" se esconde en la donación libre de la propia vida por los demás. Vivir la dimensión eucarística hasta las últimas consecuencias del amor, configurarse con Jesús crucificado y resucitado. Se identifica con la reina Ester del Antiguo Testamento. "Confío en que el Señor reciba mi vida por todos. Muchas veces pienso en la reina Ester que fue escogida para estar ante al rey en lugar de su pueblo. Soy una Ester muy pobre e impotente, pero el rey que me ha escogido es infinitamente grande y misericordioso". 
Dijo a su hermana Rosa, monja también, después que todas las diligencias para evitarles la deportación que se hicieron desde la Iglesia habían fracasado: "Ven, vamos a sacrificarnos por nuestro pueblo".

Un testimonio más de que el supuesto antagonismo entre judaísmo y cristianismo, y su influencia en el genocidio, no era visto así por muchos.

Edith Stein afirmará: "Sólo quien se experimenta a sí mismo como persona, como un todo lleno de sentido, está en condiciones de comprender a otras personas".

\section{SIMONE WEIL}

Intelectual, siente el dolor de su pueblo, aún cuan do se ha convertido al catolicismo, sin bautizarse. Simone canalizó su preocupación hacia el marxismo y luego hacia el anarquismo. En este tiempo se declara anticlerical.

En 1934, a los 25 años abandona la Universidad y se emplea como obrera en la Renault. En ese tiempo escribe: “Allí recibí, por primera vez, la marca de la esclavitud, como la marca a hierro candente que los romanos ponían en la frente de los esclavos más despreciados. Después, me he considerado siempre como una esclava".

En una estadía en Portugal, enferma escribe: "tuve de pronto la certeza de que el cristianismo es por excelencia la religión de los esclavos, que los esclavos no podían dejar de seguirla... y yo con ellos".

Vuelve brevemente a la docencia, en 1936, y luego se va a España a colaborar con grupos anarquistas, en la Guerra Civil. Entonces, la llaman "la virgen roja".

En España conoce al escritor católico, Georges Bernanos. Ambos participaron en la 
Guerra Civil, de ahí comienza a acercarse al catolicismo. Al respecto dice: “Cristo mismo descendió y me tomó".

Desde entonces, sus escritos se vuelven más místicos. Huye del régimen nazi en 1940 y se refugia en un campo, donde trabaja hasta el agotamiento. En el ' 42 parte a Londres y se enrola en la Francia libre. Enferma de tuberculosis debe ser hospitalizada. Se niega a comer; muere en agosto de 1943.

Compañera de Universidad de Simone de Beauvoir, quien escribe acerca de ella: "Me intrigaba por su gran reputación de mujer inteligente y audaz. Por ese tiempo, una terrible hambruna había devastado China y me contaron que cuando ella escuchó la noticia lloró. Estas lágrimas motivaron mi respeto, mucho más que sus dones como filósofa. Envidiaba un corazón capaz de latir a través del universo entero”.

"No es el mismo sufrimiento el que degrada y el que ennoblece; son dos sufrimientos diferentes."

\section{ETTY HILLESUM}

Nació en Middelburg (Holanda) en 1914, en el seno de una familia burguesa judía. Se sabe poco de su vida antes de la guerra. Es licenciada en derecho y además estudia lenguas eslavas, se interesa en psicología y enseña ruso. En la universidad se contacta con la resistencia de estudiantes de izquierda.

Conoce al psicólogo Julios Spier, se convierte en su paciente, en su asistente y se hacen amantes. Progresivamente evoluciona hacia una mirada más espiritual, aunque laica y aconfesional, dice en su Diario: "a la búsqueda de lo esencial y de lo verdaderamente humano". 
Entre los años '42 y '43, permaneció en Westerbork, campo de "selección” que mantenían los nazis. Consiguió un permiso especial del Consejo Hebraico, con el cual pudo ir y volver a Amsterdam llevando correspondencia a los grupos de resistencia de los prisioneros. La última parte de su Diario la escribió en el transcurso del primer mes en el campo de Westerbork.

En el año 1943 fue deportada a Auschwitz, en donde fue muerta el mismo año.

Su Diario y sus cartas dejan ver una personalidad fuerte, que supone lo que va a suceder, así escribe en 1942: "Voy a prometerte una cosa, Dios mío, una cosa muy pequeña: me abstendré de colgar en este día, como otros tantos pesos, las angustias que me inspira el futuro".

Durante los dos últimos años de su vida escribe en once cuadernos su Diario: "Lo que vivo en mi interior, y que no es únicamente mío, no tengo derecho a guardármelo para mí sola..."

Recién en 1981, salen a la luz los escritos y la historia de Etty, mostrando su manera de resistir lo que le ha tocado vivir, su triunfo está en sus escritos que alaban la vida y encuentra un sentido en su propio ser.

"E1 corazón pensante en los barracones: cartas"

\section{Algunos párrafos:}

18 de mayo de 1942

“(...) Las amenazas y el terror crecen día a día. Me cobijo entorno a la oración como un muro oscuro que ofrece reparo, me refugio en la oración como si fuera la celda de un convento; ni salgo, tan recogida, concentrada y fuerte estoy. Este retirarme en la celda cerrada de la oración, se vuelve para mí una realidad siempre más grande, y también un hecho siempre más objetivo. La concentración interna construye altos muros entre los cuales me reencuentro yo misma y mi 
totalidad, lejos de todas las distracciones. Y podré imaginarme un tiempo en el cual estaré arrodillada por días y días, hasta no sentir los muros alrededor, lo que me impedirá destruirme, perderme y arruinarme."

12 de junio de 1942

“Viernes (...) Y ahora parece que los judíos no podrán más entrar en los negocios de fruta y verdura, que deberán entregar sus bicicletas, que no podrán subir más a los tranvías ni salir de la casa después de las 8 de la noche.

Sí, me siento deprimida por estas disposiciones; esta mañana, por un momento, las he advertido como una amenaza plomiza, que buscaba sofocarme, pero no es por la disposición en sí. Me siento simplemente muy triste, y entonces esta tristeza busca confirmación. No son nunca las circunstancias exteriores, es siempre el sentimiento interior depresión, inseguridad, etc.- que da a estas circunstancias una apariencia triste o amenazante. En mi caso, funciona siempre del interior al exterior, nunca viceversa. A menudo las disposiciones más amenazadoras -y son muchas actualmente-van a quebrarse contra mi seguridad y confianza interior, y una vez resuelta dentro de mí, perdono mucho de su carga temerosa."

3 de julio de 1943, Westerbork

“Jopie, Klaas, mis queridos amigos:

Desde mi cucheta que es la tercera en alto, quiero rápidamente desencadenar una verdadera orgía de cartas, dentro de pocos días tendremos un límite a toda nuestra correspondencia, yo me volveré oficialmente "residente en el campo" y podré mandar sólo una carta cada 2 semanas y deberé entregarla abierta. Y hay todavía algunas cosas de las cuales quiero hablar con Uds. ¿Es cierto que he escrito una carta tan desalentadora? Casi no llego a creerlo. Es cierto que hay momentos en que uno cree verdaderamente no poder seguir más adelante. Pero después siempre se va adelante, también esto se aprende con el tiempo; pero el paisaje que tenemos alrededor aparece de improviso mutado, el cielo se vuelve bajo y negro, nuestro modo de 
sentir la vida sufre grandes mutaciones y nuestro corazón se vuelve completamente gris y milenario. Pero no es siempre así. Un ser humano es una cosa bien singular. La miseria que reina aquí es verdaderamente indescriptible. En las grandes barracas se vive como topos en una cloaca."

En los escritos de Etty Hellisum se manifiesta su preocupación por la guerra y la persecución de los judíos.

\section{Ana Frank}

La historia de Ana Frank es, desde luego, la más conocida. La historia de esta niña de 13 años, encerrada con su familia y unos amigos en un altillo de una fábrica en Holanda, apoyada por una pareja de holandeses, a sido llevada al cine, hemos leído su Diario por gusto o por obligación como parte de los planes y programas escolares, en fin, Ana es parte de nuestro imaginario y, acaso, nuestra primera aproximación a la Shoá.

$\mathrm{Su}$ vida transcurre alegre, con todo, en el encierro, tiene sus primeros acercamientos amorosos y, podríamos decir, que lleva una vida normal para una adolescente, en medio de una época que no es para nada normal. Su acercamiento a la persecución nazi es su pesadilla a través del recuerdo de una amiga que, al parecer fue llevada por la Gestapo, junto a su familia, a un campo de concentración, es lo que anota en su Diario.

9 de octubre de 1942

Hoy no tengo que anunciarte más que noticias deprimentes. Muchos de nuestros amigos judíos son poco a poco embarcados por la Gestapo, que no anda con contemplaciones; son transportados en furgones de ganado a Westerbork, al gran campo para judios, en Dentre. Westerbork debe ser una pesadilla; cientos y cientos están obligados a lavarse en un solo cuarto, y faltan los W.C. Duermen los unos encima de los otros, amontonados en cualquier rincón. Hombres, mujeres y niños duermen juntos. De las costumbres no hablemos: muchas de las mujeres y muchachas están encinta. 
Imposible huir. La mayoría está marcada por el cráneo afeitado, y otros, además, por su tipo judío. Si esto sucede en Holanda, ¿qué será en las regiones lejanas y bárbaras de las que Westerbork no es más que el vestíbulo? Nosotros no ignoramos que esa pobre gente será masacrada. La radio inglesa habla de cámaras de gases. Después de todo, quizá sea mejor morir rápidamente. Eso me tiene enferma.

\section{3 de enero de 1943:}

El terror reina en la ciudad. Noche y día, transportes incesantes de esa pobre gente, provista tan sólo de una bolsa al hombro y de un poco de dinero. Estos últimos bienes les son quitados en el trayecto, según dicen. Se separa a las familias, agrupando a hombres, mujeres y niños. Los niños al volver dela escuela, ya no encuentran a sus padres. Las mujeres, al volver del mercado, hallan sus puertas selladas y notan que susfamilias han desaparecido.

También les toca a los cristianos holandeses: sus hijos son enviados obligatoriamente a Alemania.

\section{Todo el mundo tiene miedo.}

Centenares de aviones vuelan sobre Holanda para bombardear y dejan en ruinas las ciudades alemanas; y a cada hora, centenares de hombres caen en Rusia y en África del Norte. Nadie está al abrigo, el globo entero se halla en guerra, y aunque los aliados ganen la guerra, todavía no se ve el final.

Podría seguir durante horas hablando de la miseria acarreada por la guerra, pero eso me desalienta de más en más. No nos queda más que aguantar y esperar el término de estas desgracias. Judios y cristianos esperan, el mundo entero espera, y muchos esperan la muerte.

"Y por la noche, al acostarme, termino mis rezos con las palabras: "gracias, Dios mío, por todo lo que es bueno, amable y hermoso", y mi corazón se regocija. Lo bueno es la seguridad de nuestro escondite, mi buena salud y todo mi ser. Lo amable es Peter, el despertar de ternura que sentimos, sin atrevernos a nombrarla o tan siquiera rozarla, pero que un día se revelara en todo su significado: el amor, el porvenir, la felicidad. Lo hermoso es el mundo, la naturaleza, la belleza y todo 
aquello que es delicado y exquisito.

Yo no pienso ya en la miseria, sino en la belleza que perdura. Ésta es la gran diferencia entre mamá y yo. Cuando alguien está desalentado y triste, su consejo siempre es: "Pensemos en las desgracias del mundo y alegrémonos de no compartirlas." Yo por mi parte, aconsejo: "Sal por los campos, contempla la naturaleza y el sol, corre al aire libre y trata de reencontrar la dicha en ti misma y en lo que te rodea."

En mi opinión el consejo de mamá no conduce a nada. ¿qué puede uno hacer si toma sobre sus hombros las penas de los demás? Quedarse anonadado y sentirse perdido. En cambio, si uno se vuelve hacia lo que es bello - La naturaleza, el sol, la libertad, lo hermoso que hay en nosotros-, nos sentimos enriquecidos. Al no perder esto de vista, encontramos nuevamente a Dios, a nosotros mismos, y recuperamos nuestro equilibrio.

El que es feliz, hace felices a los demás. Quien no pierde el valor ni la confianza, jamás perecerá por la miseria-“.

Ana Frank (7 de Marzo de 1944)

\section{A MODO DE REFLEXIÓN FINAL}

Cuatro relatos de mujeres que vivieron y murieron la Shoá. Cuatro cuidadoras podríamos decir, al menos por lo cierto que hay en sus miradas, en las cuales parecieran redimir su holocausto, aquello que presienten acabará con sus vidas. Lo entienden, lo rechazan, lo aceptan y dejan como legado finalmente a la humanidad la esperanza, al decir de Hannah Arendt.

De cierta forma es su manera de resistir, si un régimen, como el nazismo, decide aniquilar a los judíos, que es su pueblo, ellas deciden que sus muertes no serán el fin y escriben, y con sus pensamientos escritos la humanidad sobreviviente sabrá encontrar sus propios sentires, la memoria se conformará de estos retazos de vida de unas mujeres que no renegaron de sus propias muertes, porque no se resignaron a morir del todo.

Es curioso como nuestro imaginario ha trabajado con sus vivencias para sentir menos 
odio, menos impotencia, para sentirse y sentirnos menos frágiles e indefensos frente al odio generalizado desde una ideología política.

Será por eso que todas ellas piensan en la trascendencia, en la divinidad, en algo más que la humanidad y sus acciones irreversibles? Y al hacerlo se erigen como las eternas cuidadoras de la memoria humana.

Sin embargo, quiero dejar, a manera de reflexión, una cita de Hannah Arendt, de su libro “Eichmann en Jerusalén”, quizás como una acción personal, y me hago cargo de ello, que también es irreversible:

Arendt cierra así el post-iscriptum de "Eichmann en Jerusalén":

"Aquí nos ocupamos únicamente de lo que hiciste, no de la posible naturaleza inocua de tu vida interior y de tus motivos, ni tampoco de la criminalidad en potencia de quienes te rodeaban. (...) Todavía queda el hecho de haber, tú, cumplimentado, y, en consecuencia, apoyado activamente una política de asesinato masivo. El mundo de la política en nada se asemeja a los parvularios; en materia política, la obediencia y el apoyo son la misma cosa. Y del mismo modo que tú apoyaste y cumplimentaste una política de unos hombres que no deseaban compartir la tierra con el pueblo judio ni con ciertos otros pueblos de diversa nación (...) nosotros consideramos que nadie, es decir, ningún miembro de la raza humana, puede desear compartir la tierra contigo. Esta es la razón, la única razón, por la que has de ser ahorcado." (Arendt, H., 2000)

\section{BIBLIOGRAFÍA}


Arendt, Hannah, El concepto de amor en San Agustín, Ediciones Encuentro, Madrid, 2005

Arendt, Hannah, La condición humana, Paidós, Buenos Aires, 1993

Arendt, Hannah, Una revisión de la historia judía y otros ensayos, Paidós, Buenos Aires, 2005

Arendt, Hannh, Eichmann en Jerusalén: un estudio sobre la banalidad del mal, Editorial Lumen, Barcelona, 2000

Bea Pérez, Emilia, Simone Weil. La memoria de los oprimidos (Versión digital): http://books.google.cl/books?id=J1N-

$79 \mathrm{c} 6$ PrkC\&printsec $=$ frontcover $\& \mathrm{dq}=$ simone + weil $\&$ hl=es\&ei=oPYcTcn $1 \mathrm{IoG} 01 \mathrm{QfOz}$ $5 \mathrm{~W} 7 \mathrm{CW} \&$

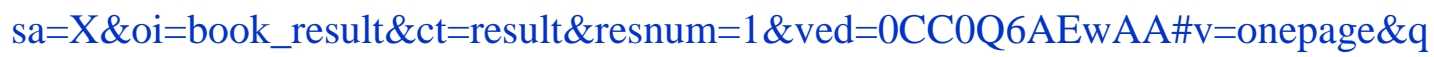
$\& \mathrm{f}=$ false Fecha de consulta: 08-01-2009.

Courtine-Denamy, Sylvie, Tres mujeres en tiempos sombrios: Edith Stein, Hannah Arendt, Simone Weil o Amor fati, Amor mundi, EDAF, Madrid, 1993.

Feldhay Brenner, Rachel, Resistencia ante el Holocausto. Edith Stein, Simone Weil, Ana Frank y Etty Hilesum (Versión digital):

http://books.google.cl/books?id=AtxL62A9PhYC\&pg=PA2\&lpg=PA2\&dq=MUJER $\mathrm{ES}+\mathrm{EN}+\mathrm{E}$

$\mathrm{L}+\mathrm{HOLOCAUSTO}+\mathrm{Y}+\mathrm{G} \% \mathrm{C} 3 \% 89 \mathrm{NERO} \&$ source $=\mathrm{bl} \&$ ots $=\mathrm{fm} 9 \mathrm{ObsOeYq \& sig=NYb}$ vkQL7y-

mSIzKb9va6JYXpZiU\&hl=es\&ei=a7caStGzJqXflQfS1KToCw\&sa=X\&oi=book_res ult\&ct=res

ult\&resnum $=8 \# \mathrm{v}=$ onepage $\& \mathrm{q}=$ MUJERES $\% 20 \mathrm{EN} \% 20 \mathrm{EL} \% 20 \mathrm{HOLOCAUSTO} \% 20 \mathrm{Y}$ $\% 20$ G\% C3\%89NERO\&f=false Fecha de consulta: 08-01-2009.

Frank, Anne, Diario de Ana Frank, Quimantú, Santiago, 1973 
Hillesum, Etty, The Letters and Diaries of Etty Hillesum 1941-1943(Versión digital): http://books.google.cl/books?id=UaMquRjHwcAC\&printsec=frontcover\&dq=etty+hi llesum\&s ource=bl\&ots=BFXRlk0JTZ\&sig=NEaU_m5hmWXPDsAWu_ozq48KDLQ\&hl=es \&ei=cvAcTf qADIP61wfOlIC4CA\&sa=X\&oi=book_result\&ct=result\&resnum $=12 \& v e d=0$ CFAQ6 AEwCw Fecha de consulta: 08-01-2009.

Ranff, Viki, Edith Stein. En busca de la verdad (Versión digital): $\mathrm{http} / / /$ books.google.cl/books?id=bJgxFJwx 1 x $8 \mathrm{C} \&$ printsec=frontcover\&dq=edith+ste in\&hl=e s\&ei=mPUcTfDnI4Sdlgfe5rjdCw\&sa=X\&oi=book_result\&ct=result\&resnum $=1 \& v e$ $\mathrm{d}=0$ CCYQ 6AEwAA\#v=onepage $\& \mathrm{q} \& \mathrm{f}=$ false Fecha de consulta: 08-01-2009.

Yad Vashem, Heroínas Cotidianas. Mujeres Judías en Tiempos del Holocausto, Israel, 2008. 